\title{
Sufficient and Comprehensive Measurement of Automobile Manufacturing Industry Performance Applying Bi-objective Super-efficiency DEA
}

\author{
Xiaodong Sun ${ }^{1, a}$, Xuliang LV ${ }^{1, b}$ and Ling $\mathrm{Li}^{1, \mathrm{c}}$ \\ ${ }^{1}$ PLA University of Science and Technology, Nanjing 210007, China; \\ axdsunlgdx@163.com, ${ }^{b}$ xllu1957@126.com, ${ }^{c}$ leonleeust@163.com
}

Keywords: automobile manufacturing industry; bi-objective DEA; super-efficiency DEA; measurement; projection; weight

\begin{abstract}
In this paper, we measure performance of automobile manufacturing industry by a new hybrid model based on bi-objective super-efficiency DEA. We propose super-efficiency DEA theory to improve conventional DEA with non-Archimedean infinitesimal, and then we take bi-objective issue into consideration to formulate a hybrid model. The proposed model has three main advantages in assessing automobile manufacturing industry performance: (i) it applies super-efficiency DEA to realize sufficient ranking of performances; (ii) non-Archimedean infinitesimal utilized in DEA can give slacks and projections, which provides optimal condition those indexes of inefficient years can be attained; (iii) bi-objective DEA can offer more comprehensive evaluation from both input-orientated and output-orientated perspectives. We illustrate the application of the proposed approach by a numerical example with data of automobile manufacturing industry enterprises in China from 1998 to 2010. The example shows the effectiveness and practicability of the new approach.
\end{abstract}

\section{Introduction}

Automobile manufacturing is one of the most important pillar industries of the national economy in China, which has becoming the battleground for the state and private enterprise. It has long industry chain, resulting in more complicated influencing factors. Thus, measuring the overall performance of automobile manufacturing industry is a subject of multiple criteria decision making (MCDM) problem, playing an instructive role in development of the industry. Many scholars have put forward some mathematical approaches to evaluate relative efficiency, for example, analytic hierarchy process (AHP) [1], grey correlation analysis [2], fuzzy comprehensive evaluation [3], data envelopment analysis (DEA) and so on, which have their own advantages and disadvantages. DEA approach, originated by Charnes, Cooper, and Rhodes, is a non-parametric approach for evaluating the relative efficiency of homogeneous decision making units (DMUs), which use similar inputs to produce similar outputs [4]. Recently, the super-efficiency model for SBM has been developed by many researchers for the purpose of ranking SBM efficient DMUs [5].

Bi-objective DEA has superiority in discrimination and projection analysis, attracting more researchers recently. For example, Ghasemi MR et al. [6] proposed a bi-objective multiple criteria DEA, which outperforms the traditional models in the aspects of discrimination power and weight dispersion, as well as requiring less computational codes. Wei Quanling et al. [7] built a bi-objective generalized DEA and point-to-set mapping projection, representing decision makers' specific preference on input and output as well as providing more possibility to determine different input and output alternatives when considering efficiency improvement. Hajiagha SHR et al. [8] also constructed a bi-objective DEA model which its solution has determined the optimal range of DMUs efficiency. 
Automobile manufacturing industry performance is influenced by several factors such as workforce, assets, liabilities, profits et al. Previous study focused on single financial index, leading to weakening of overall measurement. Current researches mostly show solicitude for multiple criteria to construct index system [9,10,11]. In this paper, we take index system into consideration from the following principles: (1) Comprehensiveness and simplicity must be concerned about simultaneously to cover the most important production indexes of automobile manufacturing enterprises. (2) Irrelevance should be thought over between every two indexes of cost and benefit. (3) Availability of index data can be another crucial factor we must take into consideration. In view of DEA structure, input and output index have their normal requirements: input is inversely proportional to the DEA efficiency; output is proportional to the DEA efficiency. Thus, we classify the indexes into two categories of cost and benefit index, which can be described as input and output respectively. The index system for measuring automobile manufacturing industry performance is illustrated as Fig. 1.

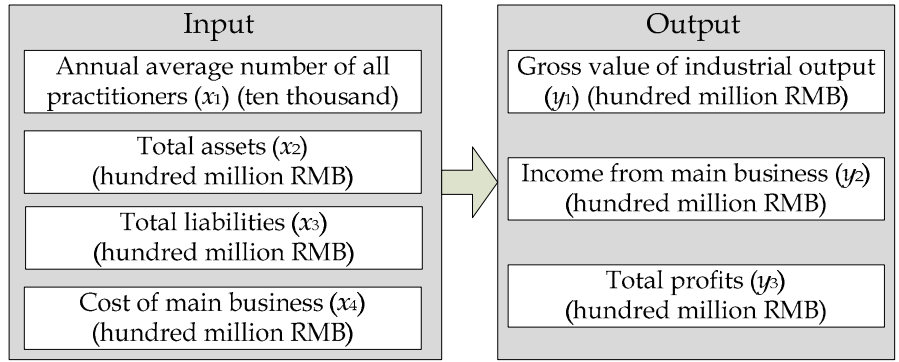

Fig. 1The index system for measuring automobile manufacturing industry performance

\section{Super-efficiency DEA model}

DEA is a widely used mathematical programming approach for comparing the multiple inputs and outputs of a set of homogenous DMUs by measuring their relative efficiency. Suppose that there are $\mathrm{n}$ $\mathrm{DMU}_{\mathrm{s}}$ to be measured where jth DMU is defined as DMUj, $\mathrm{j}=1,2, \ldots, \mathrm{n}$, consuming $m$ inputs, $\mathrm{x}_{\mathrm{ij}}$ ( $\mathrm{i}$ $=1,2, \ldots, \mathrm{m})$, producing $\mathrm{s}$ outputs, $\mathrm{y}_{\mathrm{rj}}(\mathrm{r}=1,2, \ldots, \mathrm{s})$.

DEA model for assessing the input-orientated efficiency of $\mathrm{j}_{0 \text { th }}$ DMU $\left(\mathrm{DMU}_{0}\right)$ under constant returns to scale (CRS) with non-Archimedean infinitesimal is formulated as Eq. (1). Where ê $=(1$, $1, \ldots, 1) \mathrm{T} \in \mathrm{Em}$ and $\mathrm{e}=(1,1, \ldots, 1) \mathrm{T} \in \mathrm{Es}$ are unit vectors, and $\varepsilon(\varepsilon>0)$ is a non-Archimedean infinitesimal. S+ and S- are slacks, which reflect non-radial improvement between one DMU and its optimal condition. Slack based measure can provide us more management information about improvement. We construct the model under CRS, offering us overall efficiency, which includes technical efficiency under variable returns to scale (VRS) and scale effect. Conventional DEA can be extended into SE-DEA, which is proposed as Eq. 2.

$$
\begin{array}{ll}
\min & {\left[\theta-\varepsilon\left(\hat{e}^{T} S^{-}+e^{T} S^{+}\right)\right]} \\
\text {s.t. } & \sum_{j=1}^{n} X_{j} \lambda_{j}+S^{-}=\theta X_{0} \\
& \sum_{j=1}^{n} Y_{j} \lambda_{j}-S^{+}=Y_{0} \\
& \lambda_{j} \geq 0, j=1,2, \cdots, n \\
& S^{-} \geq 0, S^{+} \geq 0
\end{array}
$$

$$
\begin{array}{ll}
\min & {\left[\alpha-\varepsilon\left(\hat{e}^{T} S^{-}+e^{T} S^{+}\right)\right]} \\
\text {s.t. } & \sum_{j=1, j \neq 0}^{n} X_{j} \lambda_{j}+S^{-}=\alpha X_{0} \\
& \sum_{j=1, j \neq 0}^{n} Y_{j} \lambda_{j}-S^{+}=Y_{0} \\
& \lambda_{j} \geq 0, j=1,2, \cdots, n, j \neq 0 \\
& S^{-} \geq 0, S^{+} \geq 0
\end{array}
$$

\section{Bi-objective super-efficiency DEA and projection}


Input-orientated DEA aims at radial variation of input and non-radial variation of both input and output, which is called slacks. Conversely, output-orientated DEA puts forward radial variation of output and non-radial slacks of both input and output, which can be formulated as Eq. (3).

$$
\begin{aligned}
& \max \left[\sigma-\varepsilon\left(\hat{e}^{T} S^{-}+e^{T} S^{+}\right)\right] \\
& \text {s.t. } \sum_{j=1}^{n} X_{j} \lambda_{j}+S^{-}=X_{0} \\
& \sum_{j=1}^{n} Y_{j} \lambda_{j}-S^{+}=\sigma Y_{0} \\
& \lambda_{j} \geq 0, j=1,2, \cdots, n \\
& S^{-} \geq 0, S^{+} \geq 0 \\
& \max \left[\beta-\varepsilon\left(\hat{e}^{T} S^{-}+e^{T} S^{+}\right)\right] \\
& \text {s.t. } \sum_{j=1, j \neq 0}^{n} X_{j} \lambda_{j}+S^{-}=X_{0} \\
& \sum_{j=1, j \neq 0}^{n} Y_{j} \lambda_{j}-S^{+}=\beta Y_{0} \\
& \lambda_{j} \geq 0, j=1,2, \cdots, n, j \neq 0 \\
& S^{-} \geq 0, S^{+} \geq 0
\end{aligned}
$$

Like input-orientated DEA, the efficiencies of efficient DMUs in output-orientated DEA are equal to unity simultaneously. We can also obtain the super-efficiency issue of output-orientated DEA as Eq. (4). Where $\sigma$ is the efficiency and $\beta$ is super-efficiency of output-orientated DEA. Unlike input-orientated SE-DEA, the super-efficiencies of efficient DMUs in output-orientated SE-DEA are less than unity.

Traditional DEA models evaluate relative efficiency of DMUs from input-orientated or output-orientated DEA respectively, which can lead to incomplete measurement. In order to provide a more comprehensive analysis of automobile manufacturing industry performance, we propose a bi-objective super-efficiency DEA model, which takes input-orientated and output-orientated DEA into consideration at the same time, formulated as follows:

$$
\gamma=\alpha / \beta
$$

Where, $\gamma$ is the bi-objective super-efficiency, which is in proportion to $\alpha$ and inversely proportional to $\beta$. Thus, we can conclude that $\gamma$ is a comprehensive bi-objective efficiency, which is proportional to performance of automobile manufacturing industry.

\section{Numerical example}

In this section, we apply the proposed bi-objective SE-DEA model to measure performance of automobile manufacturing industry enterprises in China from 1998 to 2010. Each DMU represents a year, thus there are thirteen DMUs with four inputs and three outputs. The data of inputs and outputs for automobile manufacturing enterprises in China from 2008 to 2010 have been listed in Table 1, which have been collected and sorted out by CEInet Industry Database of China.

Table 1 Input and output of automobile manufacturing enterprises in China from 1998 to 2010

\begin{tabular}{cccccccc}
\hline Year & $\mathrm{x}_{1}$ & $\mathrm{x}_{2}$ & $\mathrm{x}_{3}$ & $\mathrm{x}_{4}$ & $\mathrm{y}_{1}$ & $\mathrm{y}_{2}$ & $\mathrm{y}_{3}$ \\
\hline DMU1(1998) & 57.2 & 2468.48 & 1647.04 & 1126.91 & 1353.08 & 1347.61 & 38.12 \\
DMU2(1999) & 51.4 & 2718.26 & 1747.74 & 1335.42 & 1577.72 & 1629.98 & 56.39 \\
DMU3(2000) & 48.2 & 2892.90 & 1776.06 & 1547.06 & 1871.20 & 1920.11 & 87.80 \\
DMU4(2001) & 45.7 & 3022.23 & 1762.60 & 1900.44 & 2345.11 & 2346.51 & 150.95 \\
DMU5(2002) & 43.6 & 3391.76 & 1951.67 & 2525.40 & 3185.57 & 3155.67 & 258.37 \\
DMU6(2003) & 45.7 & 4560.95 & 2510.74 & 3951.28 & 4913.74 & 4938.56 & 463.65 \\
DMU7(2004) & 45.3 & 5384.08 & 2717.29 & 4587.40 & 5637.76 & 5521.18 & 402.19 \\
DMU8(2005) & 50.8 & 5600.46 & 3198.83 & 5104.65 & 6164.87 & 6008.50 & 258.35 \\
DMU9(2006) & 57.3 & 6996.91 & 3954.82 & 6791.21 & 8251.41 & 8162.83 & 389.49 \\
DMU10(2007 & 63.3 & 8552.60 & 4718.74 & 8657.30 & 10694.3 & 10474.2 & 642.67 \\
DMU11(2008 & 64.4 & 9801.75 & 5356.58 & 9949.31 & 11776.8 & 11883.3 & 731.99 \\
DMU12(2009 & 77.1 & 12466.4 & 7405.04 & 12828.2 & 15624.6 & 15651.2 & 1224.7 \\
DMU13(2010 & 85.8 & 16400.2 & 10164.6 & 17431.4 & 21223.6 & 21420.2 & 2139.1 \\
\hline
\end{tabular}

Data were collected by CEInet Industry Database of China (www.cei.gov.cn) 
We run model (2) and (4) to gain super-efficiencies from input-orientated and output-orientated point of view. Table 2 illustrates the comprehensive efficiency of bi-objective SE-DEA, showing that SE-DEA successfully distinguish between relative efficient years in DEA, for example, $\alpha_{5}=1.0143$, $\alpha_{6}=1.0124, \alpha_{10}=1.0384, \alpha_{11}=1.0138, \alpha_{13}=1.5699$ in input-orientated DEA, $\beta_{5}=0.9859, \beta_{6}=0.9877$, $\beta_{10}=0.9629, \beta_{11}=0.9864, \beta_{13}=0.6370$. We can conclude that 2010 performs best, and 1998 displays worst. The five years of 2002, 2003, 2007, 2008 and 2010 are relative efficient, and the rest of years are relative inefficient.

Table 2 Comprehensive efficiency of BOSE-DEA

\begin{tabular}{ccccccc}
\hline Year & $\theta$ & $\alpha$ & $\sigma$ & $\beta$ & $\gamma$ & Ranking \\
\hline DMU1(1998) & 0.9569 & 0.9569 & 1.0449 & 1.0449 & 0.9158 & 13 \\
DMU2(1999) & 0.9766 & 0.9766 & 1.0238 & 1.0238 & 0.9539 & 11 \\
DMU3(2000) & 0.9930 & 0.9930 & 1.0068 & 1.0068 & 0.9863 & 7 \\
DMU4(2001) & 0.9880 & 0.9880 & 1.0120 & 1.0120 & 0.9763 & 9 \\
DMU5(2002) & 1 & 1.0143 & 1 & 0.9859 & 1.0288 & 3 \\
DMU6(2003) & 1 & 1.0124 & 1 & 0.9877 & 1.0250 & 5 \\
DMU7(2004) & 0.9910 & 0.9910 & 1.0091 & 1.0091 & 0.9821 & 8 \\
DMU8(2005) & 0.9722 & 0.9722 & 1.0286 & 1.0286 & 0.9452 & 12 \\
DMU9(2006) & 0.9830 & 0.9830 & 1.0173 & 1.0173 & 0.9663 & 10 \\
DMU10(2007) & 1 & 1.0384 & 1 & 0.9629 & 1.0784 & 2 \\
DMU11(2008) & 1 & 1.0138 & 1 & 0.9864 & 1.0278 & 4 \\
DMU12(2009) & 0.9955 & 0.9955 & 1.0045 & 1.0045 & 0.9910 & 6 \\
DMU13(2010) & 1 & 1.5699 & 1 & 0.6370 & 2.4645 & 1 \\
\hline
\end{tabular}

\section{Summary}

This paper proposes a new approach for measuring the performance of automobile manufacturing industry based on a hybrid DEA model with the combination of super-efficiency and bi-objective DEA. We build the index system for measuring automobile manufacturing industry performance following the principles of comprehensiveness, irrelevance and availability. The proposed model enables us to (i) overcome unsatisfactory differentiation of efficient years, (ii) obtain more abundant management information about optimal condition those inefficient years can be attained, (iii) realize more comprehensive performance assessment. The numerical example presents how the hybrid model works effectively. Further work based on the framework suggested in this paper could extend the hybrid model to include heterogeneous, fuzzy and mixed-sign interval data in automobile manufacturing industry performance indexes, which will provide more practical analysis. A more comprehensive measurement of automobile manufacturing industry performance based on DEA can also be a meaningful subject of concern to be further researched.

\section{Acknowledgements}

This work is supported by Foundation of National Key Laboratory on Environmental Electromagnetic Effects and Electro-Optic Engineering (Grant No. FD2015008) and General Armament Department Foundation of China (Grant No. 9140C95020414JB25002).

\section{References}

[1] C. H. Chou, G. S. Liang, and H. C. Chang, "A fuzzy AHP approach based on the concept of possibility extent”, Quality \& Quantity, vol. 47, no. 1, (2013), pp. 1-14. 
[2] M. S. Tsai and F. Y. Hsu, "Application of Grey Correlation Analysis in Evolutionary Programming for Distribution System Feeder Reconfiguration”, IEEE Transactions on Power Systems, vol. 25, no. 2, (2010), pp. 1126-1133.

[3] W. W. Chu, Y. G. Li, C. Q. Liu, W. P. Mou, and L. M. Tang, “A manufacturing resource allocation method with knowledge-based fuzzy comprehensive evaluation for aircraft structural parts”, International Journal for Production Research, vol. 52, no. 11, (2014), pp. 3239-3258.

[4] A. Charnes, W. W. Cooper, and E. Rhodes, "Measuring the efficiency of decision making units", European Journal of Operational Research, vol. 2, no. 6, (1978), pp. 429-444.

[5] H. H. Fang, H. S. Lee, S. N. Hwang, and C. C. Chung, "A slacks-based measure of super-efficiency in data envelopment analysis: An alternative approach", Omega, vol. 41, no. 4, (2013), pp. 731-734.

[6] Ghasemi MR, Ignatius Joshua, and Emrouznejad Ali, "A bi-objective weighted model for improving the discrimination power in MCDEA", European Journal of Operational Research, vol. 233, no. 3, (2014), pp. 640-650.

[7] Q. L. Wei, H. Yan, and L. Xiong, “A bi-objective generalized data envelopment analysis model and point-to-set mapping projection", European Journal of Operational Research, vol. 190, no. 3, (2008), pp. 855-876.

[8] Hajiagha SHR, Mahdiraji HA, Zavadskas EK, and Hashemi SS, "A Fuzzy Data Envelopment Analysis Approach based on Parametric Programming", International Journal of Communications \& Control, vol. 8, no.4 4, (2013), pp. 594-607.

[9] Fuentes R, "Efficiency of travel agencies: A case study of Alicante, Spain”, Tourism Management, vol. 32, no. 1, (2011), pp. 75-87.

[10] Drauz R, "Re-insourcing as a manufacturing-strategic option during a crisis-Cases from the automobile industry", Journal of Business Research, vol. 67, no. 3, (2014), pp. 346-353.

[11] Lavatelli I, Schaub K, Caragnano G, "Correlations in between EAWS and OCRA Index concerning the repetitive loads of the upper limbs in automobile manufacturing industries", Work-A Journal of Prevention Assessment \& Rehabilitation, vol. 41, no. s1, (2012), pp. 4436-4444. 